\title{
Bifid Frontal Superficial Temporal Artery Island Flap for Periocular Reconstruction Post Tumor Excision
}

\author{
RAAFAT A. ANANI, M.D.; MOHAMMED NASR, M.D. and MAHFOUZ AHMED, M.D., M.R.C.S. \\ The Department of General Surgery, Plastic and Reconstructive Surgery Unit, Faculty of Medicine, Zagazig University, Egypt
}

\begin{abstract}
Background and Objectives: Reconstruction of periocular defects resulting after tumor excision is representing a great challenge especially if it involves more than a single zone. This study was done to evaluate the efficacy of bifid frontal superficial temporal artery island flap in reconstruction of complex periocular defects involving zones I, II and IV together.

Patients and Methods: This study included 11 patients with combinations of zones I, II and IV periocular defects after excision of large basal cell carcinomas. All defects were reconstructed using a bifid island flap based on branches of the frontal division of the superficial temporal artery.

Results and Conclusion: Apart from one flap, which developed distal necrosis, all flaps did well. All patients were satisfied to very satisfied about aesthetic and functional outcome. Bifid frontal superficial temporal artery island flap is considered a valuable and good option for reconstruction of periocular defects involving zones I, II and IV.
\end{abstract}

Key Words: Periocular reconstruction - Bifid frontal superficial temporal artery island flap.

\section{INTRODUCTION}

Malignant tumors involving the eyelids represent 5 to $10 \%$ of all skin cancers [1]. Tumor excision results in challenging periocular defects to reconstructive surgeons owing to the requirement of achieving better function and cosmoses. The available options for its reconstruction include; skin grafting, local flaps and may be free flaps [2-5].

Spinelli and Jelks, 1993 were the first to make classification of eye lid defects into zones; zone I (upper eye lid), zone II (lower eye lid), zone III (medial canthus) and zone IV(lateral canthus) [2].

\section{Anatomical basis of the flap:}

Nearly at the level of zygomatic arch, superficial temporal artery divides into two terminal divisions which are the frontal or the anterior and the parietal or the posterior. The frontal is wider in diameter, longer in length and more constant than the parietal one [6-8]. The frontal division courses anterosuperior then in most cases it is divides into two branches superior (posterior) and inferior (anterior) one. However sometimes a third branch called central may be also present (Fig. 1a,b) $[\mathbf{9 , 1 0 ]}$. Use of an island flap based on superficial temporal artery itself or on its frontal division has been described in literature for coverage of facial defects [11,12]. In this study we present a new technique using an island bifid flap based on the branches of the frontal division of superficial temporal artery for coverage of defects involving zones I, II and IV of eyelids together. To our knowledge, this technique was not described before, so it could be considered a novel one.

\section{PATIENTS AND METHODS}

Over 31 month's period, from April 2015 to November 2017, 11 cases of periocular defects ( 8 males and 3 females) were reconstructed using bifid frontal superficial temporal artery island flap in Plastic Surgery Unit, Zagazig University Hospitals. All defects resulted after excision of basal cell carcinomas, 8 of them were recurrent. They were affecting the lateral canthus as well as both upper and lower eyelids (zones I, II and IV according to Spinelli and Jelks classification) [2]. The patient's demographics, lesions description, defect sizes, flap dimensions, complications and additional procedures are summarized in Table (1).

\section{Operative technique:}

Before starting the operation, the superficial temporal, frontal division and its branches were identified using hand held $8 \mathrm{MHz}$ Doppler. All procedures were done under general anesthesia. All patients received one dose of $1 \mathrm{gm}$ cefotaxim one hour before surgery and continued twice daily postoperatively for one week in addition to local chloramphenicol eye drops. During operation, the basal cell carcinoma was excised with $10 \mathrm{~mm}$ safety 
margin (Fig. 2). Safety margins were confirmed to be free of malignancy after frozen section biopsy examination. In all cases, full thickness excision of the outer part of both eyelids together with the outer canthus was done. However, the bulbar conjunctiva was intact in all cases (Fig. 3). The flap dimensions were designed to be slightly larger than the resulting defects and the pedicle to be slightly longer than its distance from the defect to help its safe rotation (Fig. 3).

The island skin paddle was first dissected ovoid in shape including branches of the frontal division of superficial temporal artery. A longitudinal incision within the hairy area over the vessel (frontal division of superficial temporal) course was then done. The dissection of the pedicle was then started sub-dermal with only thin layer of fat was left attached to the skin to avoid its necrosis and all subcutaneous tissues was kept with the flap pedicle. The dissection was continued from distal to proximal till the origin of frontal division from the superficial temporal artery with each time testing the adequacy to reach the defect (Fig. 4). When dissection completed and heamostasis was secured, a wide tunnel was then created to allow the flap to reach the defect (Fig. 5). The flap was then bifid with the help of transillumination to highlight the branches of the frontal division. Two branches were seen in most cases with exception of one, which showed a third central branch that was included with the lower part. The flap was then in-setted to reconstruct the upper and lower eyelids as well as the lateral canthal missing defects. Palpebral conjunctiva was reconstructed by buccal mucosal graft that lined the undersurface of the flap facing the globe (Fig. 6). All donor site defects except in one patient were closed using thick split thickness skin grafting.
The patients were discharged on the third postoperative day. Suture removal was done on the $7^{\text {th }}$ day. Then, repeated dressing of the donor site was done till the graft healed well. A programmed followed-up regimen after 2 weeks, 2 months, 6 months, one year and 1.5 years was done. Patient's satisfaction was assessed using a questionnaire made of 4 items. The items included; good color match, symmetry with opposite side, ability to feely open and close eyelids, suggest same procedure to others. Item response were scored using five point scale (strong agree $=4$, agree $=3$, not sure $=2$, not agree $=1$, strong not agree $=0$ ). The summation of the points (ranged from 16 points which mean very satisfied to zero which mean not satisfied) dichotomized the result into three groups; we consider 16 response very satisfied, 12 to 15 response satisfied and any response else is not satisfied.

\section{RESULTS}

The size of the flaps ranged from $3.4 \times 6.5$ to $4 \times$ 8.6. The postoperative period was uneventful except some postoperative congestion in 8 flaps (Fig. 7) which was relieved spontaneously within one week. All flaps survived completely without complications except one (1/11) where a distal necrosis affected its lower part. Debridement and re-insetting was done. After that, it healed well. Histopathologic examination of the excised specimens showed basal cell carcinoma with clear surgical margins in all patients. We did not notice recurrences during the follow-up period. Results of patient's satisfaction questionnaire study are summarized in Table (2). Postoperative appearance of the patient is illustrated in (Fig. 8).

Table (1): Patient's demographics, lesions description, defect sizes, flaps size, complications and additional procedures.

\begin{tabular}{|c|c|c|c|c|c|c|c|c|}
\hline Patient No. & Age/Sex & Side & $\begin{array}{l}\text { Upper eyelid } \\
\text { defect in } \mathrm{cm}\end{array}$ & $\begin{array}{l}\text { Lower eyelid } \\
\text { defect in } \mathrm{cm}\end{array}$ & $\begin{array}{l}\text { Lateral canthus } \\
\text { defect in } \mathrm{cm}\end{array}$ & $\begin{array}{l}\text { Flap } \\
\text { dimensions } \\
\text { in } \mathrm{cm}\end{array}$ & Complications & $\begin{array}{l}\text { Additional } \\
\text { Procedures }\end{array}$ \\
\hline 1 & $\mathrm{M} / 74$ & Left & $1.5 \times 2$ & $1.4 \times 2.1$ & $2.5 \times 3.2$ & $3.3 \times 8$ & Congestion & None \\
\hline 2 & $\mathrm{M} / 68$ & Right & $1.4 \times 2$ & $1.3 \times 1.8$ & $2.4 \times 3.5$ & $3.2 \times 8.5$ & Congestion & None \\
\hline 3 & $\mathrm{~F} / 72$ & Right & $1.4 \times 2$ & $1.5 \times 1.7$ & $2.5 \times 3.5$ & $3.5 \times 7.6$ & Congestion & None \\
\hline 4 & M/63 & Left & $1.3 \times 2.1$ & $1.6 \times 2$ & $2.7 \times 3.2$ & $3.4 \times 6.5$ & Distal necrosis & $\begin{array}{l}\text { Debridement } \\
\text { \& reinsetting }\end{array}$ \\
\hline 5 & $\mathrm{~F} / 58$ & Left & $1.7 \times 2.2$ & $1.4 \times 1.7$ & $2.8 \times 3.5$ & $3.5 \times 7.5$ & None & None \\
\hline 6 & $\mathrm{M} / 70$ & Right & $1.6 \times 2$ & $1.5 \times 2.1$ & $3 \times 4$ & $3.7 \times 8.2$ & Congestion & None \\
\hline 7 & $\mathrm{~F} / 65$ & Right & $1.4 \times 1.8$ & $1.8 \times 2.2$ & $3.2 \times 3.4$ & $3.5 \times 7.8$ & None & None \\
\hline 8 & $\mathrm{M} / 62$ & Left & $1.8 \times 2.2$ & $1.6 \times 2$ & $3.2 \times 4$ & $3.8 \times 8.5$ & Congestion & None \\
\hline 9 & $\mathrm{~F} / 73$ & Right & $1.5 \times 2$ & $1.7 \times 2.3$ & $3.1 \times 4$ & $3.6 \times 8.5$ & Congestion & None \\
\hline 10 & $\mathrm{M} / 67$ & Left & $1.8 \times 2.1$ & $1.7 \times 2$ & $3.1 \times 4.1$ & $4 \times 8.6$ & Congestion & None \\
\hline 11 & $\mathrm{~F} / 60$ & Left & $1.3 \times 1.8$ & $1.6 \times 2.1$ & $2.4 \times 3.5$ & $3.4 \times 8$ & Congestion & None \\
\hline
\end{tabular}


Table (2): Results of patient's satisfaction questionnaire of all studied patients.

\begin{tabular}{lccccccccccc}
\hline Patient N./character & 1 & 2 & 3 & 4 & 5 & 6 & 7 & 8 & 9 & 10 & 11 \\
Color match & 4 & 4 & 4 & 4 & 4 & 4 & 4 & 4 & 4 & 4 & 4 \\
Symmetry & 4 & 3 & 4 & 2 & 4 & 3 & 4 & 2 & 4 & 4 & 2 \\
Eyelid movement & 4 & 4 & 4 & 3 & 4 & 4 & 4 & 3 & 4 & 4 & 4 \\
Suggest procedure to others & 4 & 3 & 4 & 3 & 4 & 4 & 4 & 4 & 4 & 4 & 2 \\
& & & & & & & & & & & \\
\hline Total Score & 16 & 14 & 16 & 12 & 16 & 15 & 16 & 13 & 16 & 16 & 12 \\
Degree of satisfaction & VS & $\mathrm{S}$ & VS & S & VS & S & VS & S & VS & VS & S \\
\hline
\end{tabular}

$\mathrm{S}=$ Satisfied. $\quad$ VS $=$ Very satisified.

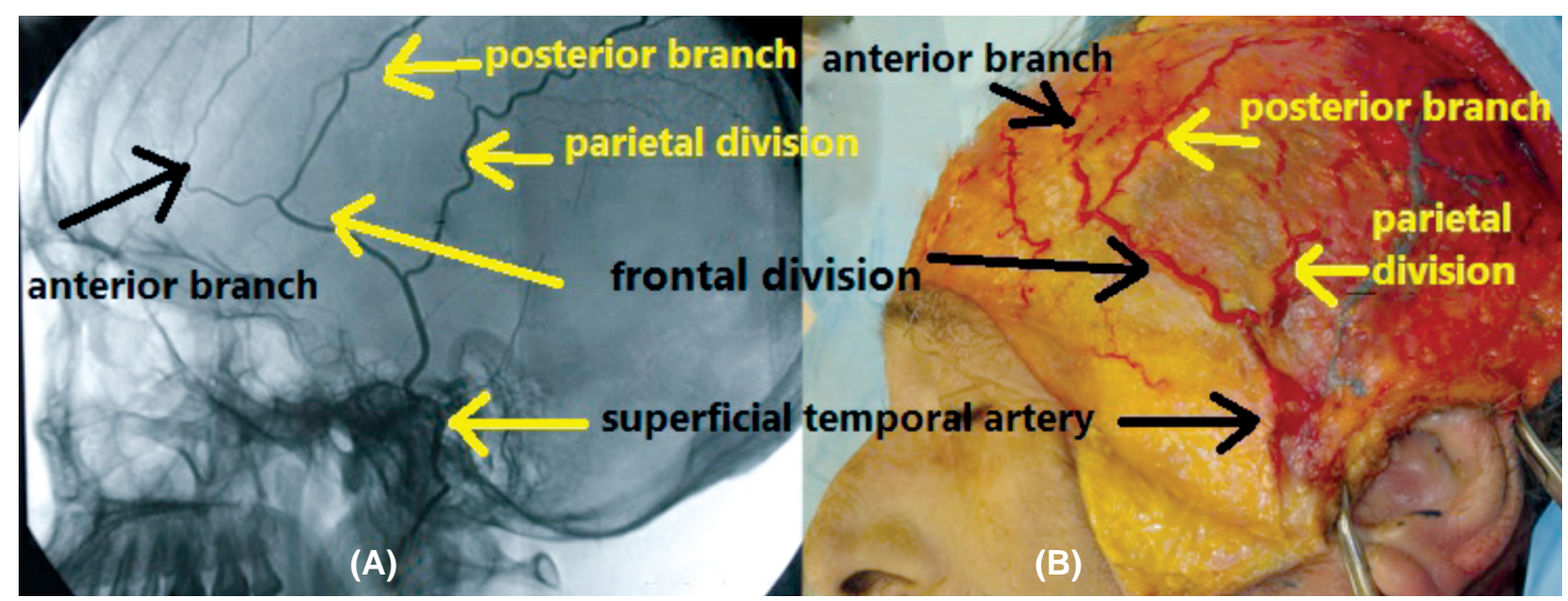

Fig. (1): Digital subtraction angiography (A) and cadaveric dissection (B) show the superficial temporal artery dividing into frontal and parietal divisions and the branching of the frontal one into anterior and posterior branches [9].

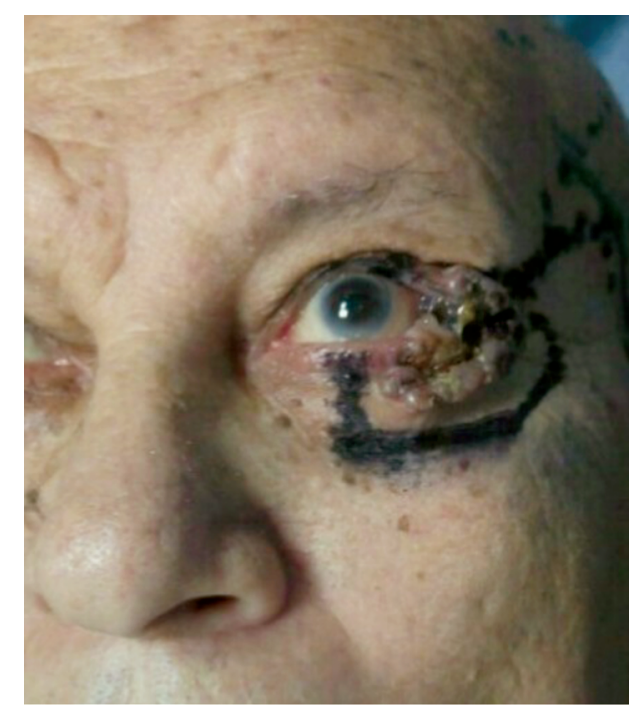

Fig. (2): Basal cell carcinoma involving zones $1,2 \& 4$ of left periocular region and the limits of resection.

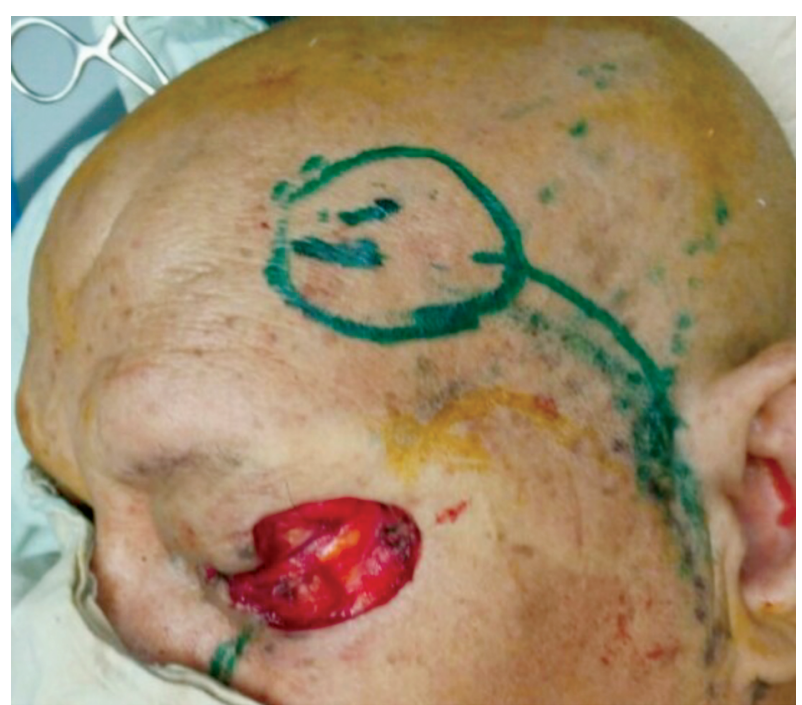

Fig. (3): The resulting defect after resection and the design of the flap. 


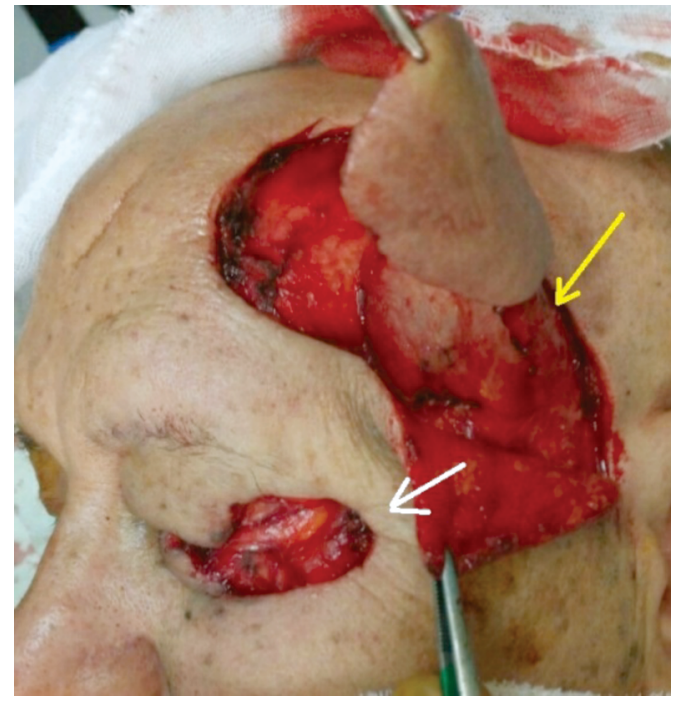

Fig. (4): The flap totally harveseted as an island attached only to the frontal division of superficial temporal vessles (yellow arrow) with tunnel created (white arrow).

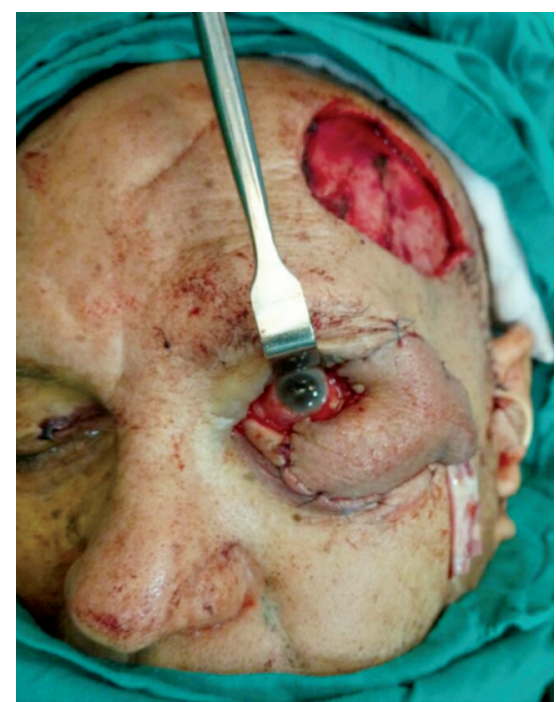

Fig.(6): The flap bifid and insetted to reconstruct both upper and lower lids with adequate palpebral fissure and lined with buccal mucosal graft to reconstruct the palpebral conjunctiva.

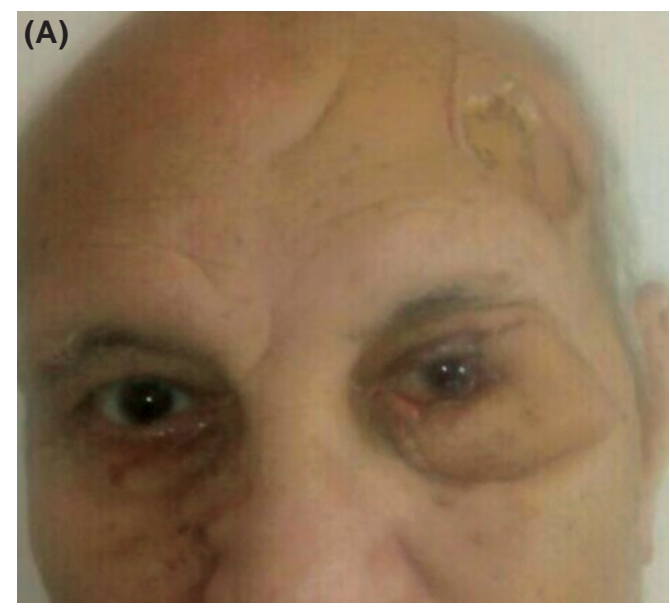

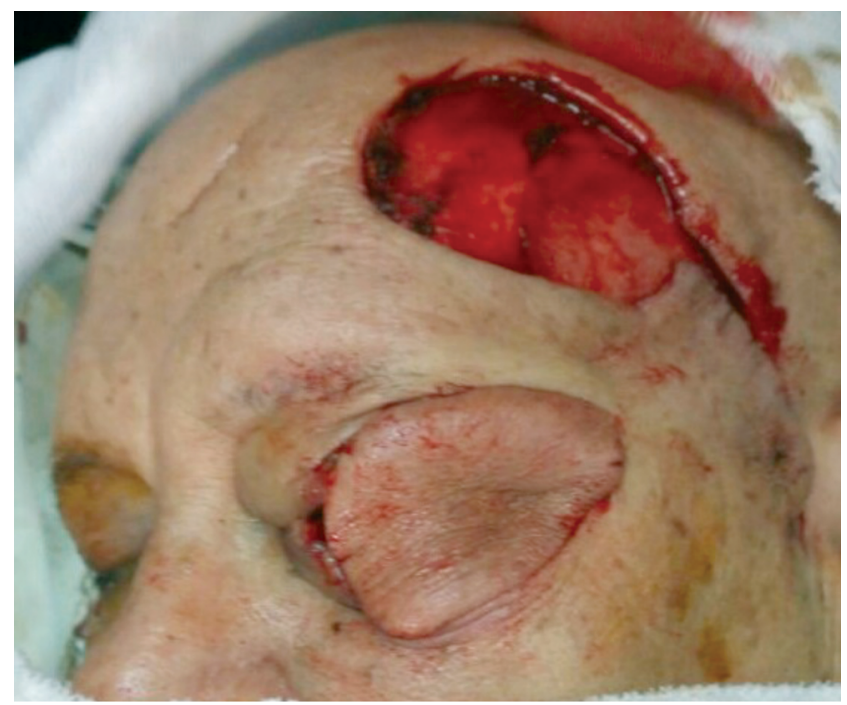

Fig. (5): The flap reached the defect without tension after passing through the created wide subcutaneous tunnel.

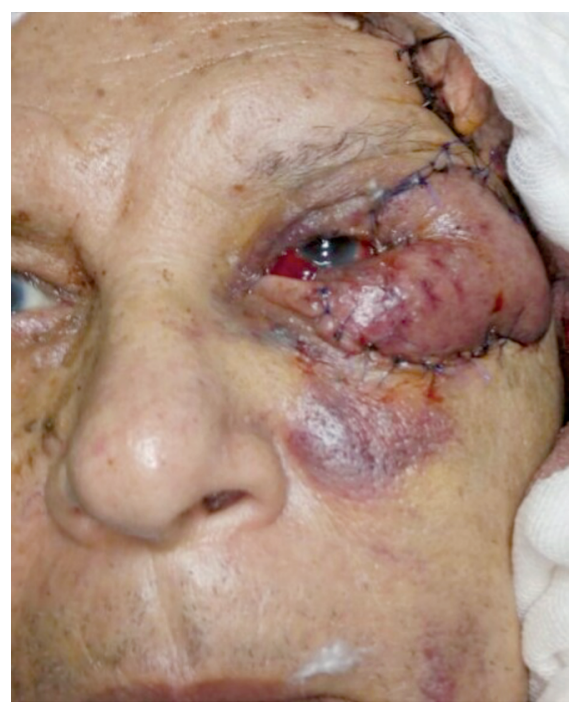

Fig. (7): Mild postoperative congestion of the flap.

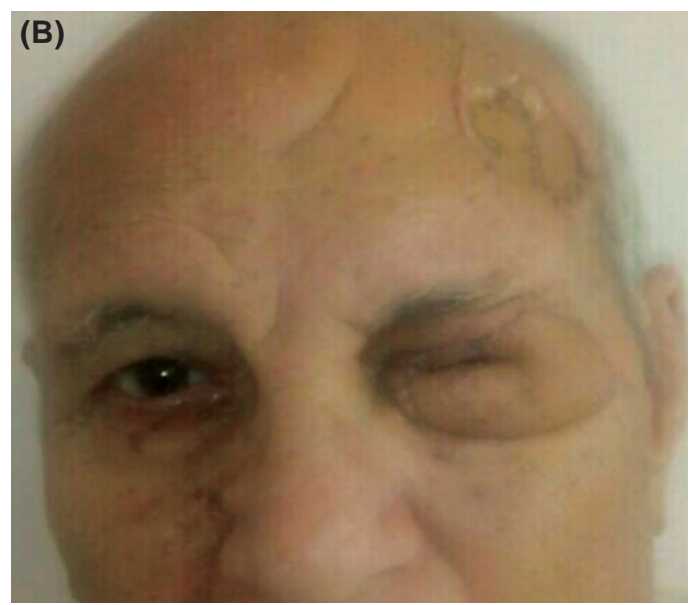

Fig. (8): The late postopeartive appearance with accepted eye opening (A), closure (B). 


\section{DISCUSSION}

Of all skin tumors about $5-10 \%$ are affecting the eyelids [1]. Basal cell carcinoma is the most common skin cancer affecting the periocular area [13].

Periocular area is a special one owing to both functional and personal identity identification. It has a complex shape and composition rendering its reconstruction a great challenge to plastic surgeons. The goals of eyelid reconstructive surgery are achieving a good function, color match, smooth surfaces of both the margins and inner aspects, provides corneal protection, all these should be in side to side with optimum cosmoses. Several reconstructive options have been reported for its reconstruction [2-4].

Superficial temporal artery island flap was described in literature. Its drawbacks are presence of hair, sacrifice of its two main divisions and the two stages if prefabricated [12,14]. Bifurcated superficial temporal island flap utilizing both frontal and parietal divisions was also previously reported for periocular defect reconstruction [15-17]. However, the parietal branch territory is hairy so frequently a hair ablation method is required, and the resulting Y shaped scar is another disadvantage.

Frontal artery is the larger of the two terminal divisions of the superficial temporal artery. It supplies a hairless wide area with good color match and texture comparable to eyelids skin [18]. Bhattacharyla et al., 2006 described frontal island flap of superficial temporal artery for perioral reconstruction [11].

Cadaveric dissection studies $[\mathbf{1 0 , 1 9 ]}$ as well as Studies utilizing either digital subtraction angiography or three-dimensional computerized tomographic angiography $[\mathbf{2 0 , 2 1 ]}$ demonstrated that the frontal division is more constant and less liable to anatomical variations than the parietal one. It is wider in diameter $(1.4 \mathrm{~mm}$ versus $1.3 \mathrm{~mm})$, longer in length (106mm versus $99 \mathrm{~mm})$. So, either it or its branches could be used as a pedicle for microvascular transfer.

Omari et al., 2012 reported a case of island flap based on anterior branch of frontal division of superficial temporal for contracted socket with a successful result [22].

Depending on the previous anatomical and clinical studies, we added a new island flap. It depends on the two branches of the frontal division of the superficial temporal artery. Preoperative
Doppler studies and intra-operative trans-illumination help to define their course, which proved constant in all cases of the study. It is almost hairless flap that gives good color match and texture to both eyelids. The flap harvesting is easy and the planes of dissection are clear.

In spite of the wide tunnel created to deliver the flap to the defect, early postoperative mild congestion developed in $8 / 11$ cases. The cause is unclear. There may be a relative higher arterial inflow than the capacity of the venous drainage in the early postoperative period that improves by time. All cases of the study passed a smooth postoperative course. Only one case (1/11) developed partial distal flap necrosis and it healed well after debridement and resuturing.

The functional outcome was excellent regarding smooth opening and closure of eyelids. The only drawback was the need for split thickness skin grafting for donor site closure in most cases. Regarding patient's satisfaction, 6/11 (55\%) of them were very satisfied and 4/11 (45\%) were satisfied while no patients were unsatisfied. This adds to the merits of this flap.

\section{Conclusion:}

Bifid frontal superficial temporal artery island flap is easily dissected due to distinct anatomical landmarks. It provides adequate hairless coverage, with good color and texture match for complex eyelid defects involving zones zones I, II and IV. It is a single stage procedure and it preserves the parietal division for use in any other future defects. All patients were satisfied functionally and aesthetically. The only disadvantage is the skin grafting of the donor site. The flap is considered an innovation one for covering these challenging defects.

\section{REFERENCES}

1- Cook B.E. JR and Bartley G.B.: Epidemiologic characteristics and clinical course of patients with malignant eyelid tumors in an incidence cohort in Olmsted County, Minn2004esota. Ophthalmology, 106: 746, 1999.

2- Spinelli H.M. and Jelks G.W.: Periocular reconstruction: A systematic approach. Plast. Reconstr. Surg., 91: 1017, 1993.

3- Mathijssen I.M. and Vander Meulen J.C.: Guidelines for reconstruction of the eyelids and canthal regions. J. Plast. Reconstr. Aesthet. Surg., 63: 1420, 2010.

4- Sharma V., Benger R. and Martin P.A.: Techniques of periocular reconstruction. Indian J. Ophthalmo., 54: 149, 2006.

5- Bowman P.H., Fosko S.W. and Hartstein M.E.: Periocular reconstruction. Semin. Cutan. Med. Surg., 22: 263, 2003. 
6- Berkowitz K.B.: Head and neck anatomy, face and scalp. In Standring S. editor. Gray's Anatomy, The anatomical basis of clinical practice, $39^{\text {th }}$ ed. Elsevier Churchill Livingstone, 497, 2005.

7- Mathes S.J. and Nahai F.: Regional Flaps: Anatomy and Basic Techniques In: Reconstructive Surgery Principles, Anatomy, Technique Volume 1. Churchill Livingstone, 367, 1997.

8- Tan O., Atik B. and Ergen D.: Temporal Flap Variations for Craniofacial Reconstruction. Plast. Reconstr. Surg., 119: 152, 2007

9- Zhou R., Wang C., Qian Y. and Wang D.: Combined flaps based on the superficial temporal vascular system for reconstruction of facial defects. J. Plast. Reconstr. Aesthet. Surg., 68: 1235, 2015.

10- Aveta A., Brunetti B., Tenna S., Segreto F. and Persichetti P.: Superficial temporal artery perforator flap: Anatomic study of number and reliability of distal branches of the superficial temporal artery and clinical applications in three cases. Microsurgery, 37: 924, 2017.

11- Bhattacharya V., Reddy G.R., Bashir S.A. and Goyal S.: An island flap based on the anterior branch of the superficial temporal artery for perioral defects. Indian Journal Plast. Surg., 39: 136, 2006.

12- Ozdemir R., Sungur N., Sensöz O., Uysal A.C., Ulusoy M.G., Ortak T. and Baran C.N.: Reconstruction of facial defects with superficial temporal artery island flaps: A donor site with various alternatives. Plast. Reconstr. Surg., 109: 1528, 2002.

13- Abdi U., Tyagi N., Maheshwari V., Gogi R. and Tyagi S.P.: Tumours of eyelid: A clinicopathologic study. J. Indian Medical Associat., 94: 405, 1996.

14- Altindas M., Yucel A., Ozturk G., Sarac M. and Kilic A.: The Prefabricated Temporal Island Flap for Eyelid and Eye Socket Reconstruction in Total Orbital Exenteration Patients. Ann. Plast. Surg., 65: 177, 2010.
15- Elbanoby T.M., Elbatawy A., Aly G.M., Ayad W., Helmy Y., Helmy E., Sholkamy K., Dahshan H. and Al-Hady A.: Bifurcated Superficial Temporal Artery Island Flap for the Reconstruction of a Periorbital Burn: An Innovation. Plast. Reconstr. Surg. Glob. Open, 17: 748, 2016.

16- Zhou R., Wang C., Qian Y. and Wang D.: Combined flaps based on the superficial temporal vascular system for reconstruction of facial defects. J. Plast. Reconstr. Aesthet. Surg., 68: 1235, 2015.

17- Ologlu H.C., Kocer U., Oruc M., Sahin B. and Ozdemir R.: Axial Bilobed Superficial Temporal Artery Island Flap (Tulip Flap): Reconstruction of Combined Defects of the Lateral Canthus Including the Lower and Upper Eyelids. Plast. Reconstr. Surg., 119: 2080, 2007.

18- Yan Z., Jianhui Z., Xiaoyan W., Chenggang Y., Wei X., Yong L. and Xianjie M.: The application of axial superficial temporal artery island flap for repairing the defect secondary to the removal of the lower eyelid basal cell carcinoma. Br. Journal of Oral and Maxillofacial Surgery, 52: 72,2014

19- Beheiry E.E. and Abdel-Hamid F.A.: An anatomical study of the temporal fascia and related temporal pads of fat. Plast. Reconstr. Surg., 119: 136, 2007.

20- Medved F., Manoli T., Medesan R., Esfahani B.J., Stahl S.E., Schaller H.E., Brodoefel H., Ernemann U. and Korn A.: In vivo analysis of the vascular pattern of the superficial temporal artery based on digital subtraction angiography. Microsurgery, 35: 380, 2015.

21- Kim B.S., Jung Y.J., Chang C.H. and Choi B.Y.: The anatomy of the superficial temporal artery in adult koreans using 3-dimensional computed tomographic angiogram: Clinical research. J. Cerebrovasc. Endovasc. Neurosurg., 15: 145, 2013.

22- Omori N., Mitsukawa N., Kubota Y. and Satoh K.: Reconstruction of a contracted eye socket using an anterofrontal superficial temporal artery island flap and scapha composite grafting in an elderly patient. J. Plast. Reconstr. Aesthet. Surg., 65: 1722, 2012. 